\title{
Effects of pro-inflammatory cytokines on expression of kynurenine pathway enzymes in human dermal fibroblasts
}

\author{
Linnéa Asp ${ }^{1}$, Anne-Sofie Johansson ${ }^{1}$, Amandeep Mann¹, Björn Owe-Larsson², Ewa M Urbanska ${ }^{3,4}$, Tomasz Kocki ${ }^{3}$, \\ Magdalena Kegel ${ }^{5}$, Göran Engberg ${ }^{5}$, Gabriella BS Lundkvist ${ }^{1}$ and Håkan Karlsson ${ }^{1 *}$
}

\begin{abstract}
Background: The kynurenine pathway (KP) is the main route of tryptophan degradation in the human body and generates several neuroactive and immunomodulatory metabolites. Altered levels of KP-metabolites have been observed in neuropsychiatric and neurodegenerative disorders as well as in patients with affective disorders. The purpose of the present study was to investigate if skin derived human fibroblasts are useful for studies of expression of enzymes in the KP.
\end{abstract}

Methods: Fibroblast cultures were established from cutaneous biopsies taken from the arm of consenting volunteers. Such cultures were subsequently treated with interferon (IFN)- $\gamma 200 \mathrm{U} / \mathrm{ml}$ and/or tumor necrosis factor (TNF)- $\alpha, 100 \mathrm{U} / \mathrm{ml}$ for 48 hours in serum-free medium. Levels of transcripts encoding different enzymes were determined by real-time PCR and levels of kynurenic acid (KYNA) were determined by HPLC.

Results: At base-line all cultures harbored detectable levels of transcripts encoding KP enzymes, albeit with considerable variation across individuals. Following cytokine treatment, considerable changes in many of the transcripts investigated were observed. For example, increases in the abundance of transcripts encoding indoleamine 2,3-dioxygenase, kynureninase or 3-hydroxyanthranilic acid oxygenase and decreases in the levels of transcripts encoding tryptophan 2,3-dioxygenase, kynurenine aminotransferases or quinolinic acid phosphoribosyltransferase were observed following IFN- $\gamma$ and TNF- $\alpha$ treatment. Finally, the fibroblast cultures released detectable levels of KYNA in the cell culture medium at base-line conditions, which were increased after IFN- $\gamma$, but not TNF- $\alpha$, treatments.

Conclusions: All of the investigated genes encoding KP enzymes were expressed in human fibroblasts. Expression of many of these appeared to be regulated in response to cytokine treatment as previously reported for other cell types. Fibroblast cultures, thus, appear to be useful for studies of disease-related abnormalities in the kynurenine pathway of tryptophan degradation.

Keywords: human, fibroblast, kynurenine pathway, gene expression, cytokine

\section{Introduction}

The kynurenine pathway (KP) is the main route of tryptophan degradation in the human body and generates several neuroactive and immunomodulatory metabolites $[1,2]$. KP activity has the potential to affect a range of neurotransmitter systems in the brain including

\footnotetext{
* Correspondence: hakkar@ki.se

'Department of Neuroscience, Karolinska Institutet, Retzius väg 8, 17177 Stockholm, Sweden

Full list of author information is available at the end of the article
}

glutamatergic, cholinergic and serotonergic transmission [2-4]. Indeed, altered levels of KP-metabolites have been observed in neuropsychiatric and neurodegenerative disorders [5-8] as well as in patients with affective disorders [9-13]. While experimental studies support an involvement of kynurenine metabolites in the pathogenesis of both psychiatric and neurodegenerative disorders [14-20], the underlying cause of the dysregulation of kynurenine metabolism in these disorders is not known.

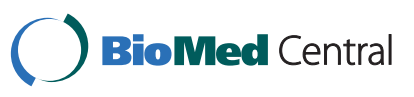

(c) 2011 Asp et al; licensee BioMed Central Ltd. This is an Open Access article distributed under the terms of the Creative Commons Attribution License (http://creativecommons.org/licenses/by/2.0), which permits unrestricted use, distribution, and reproduction in any medium, provided the original work is properly cited. 
Several studies have shown that infections activate the $\mathrm{KP}$, which thereby appear to serve both as a direct defense mechanism and as a means of modulating the immune response [1,21]. The enzyme indoleamine 2,3dioxygenase (IDO1) is the first and rate-limiting step of this pathway and is highly induced by the pro-inflammatory cytokine interferon (IFN) $-\gamma[22,23]$. However, it is not clear if pro-inflammatory cytokines affect expression of genes encoding other enzymes of the KP. While human fibroblasts have previously been employed for studying the role of IDO1 in controlling experimental infections [24-26], expression or functionality of genes encoding downstream enzymes in the KP have not been investigated in such cells. Since alterations in the KP may potentially reflect the pathophysiology of several neuropsychiatric disorders, it is of major importance to study the KP in primary cells obtained from humans. In the present study, we have established human ex vivo skin fibroblast cell cultures as a successful approach to study the KP. We investigated if transcripts encoding enzymes in the kynurenine pathway can be detected in these cells and if their relative abundances are modulated by IFN- $\gamma$ and/or tumor necrosis factor (TNF)- $\alpha$.

\section{Materials and methods}

\section{Tissue isolation and culture}

To establish fibroblast cultures, a cutaneous biopsy was taken from the arm of seven consenting volunteers recruited at Karolinska University Hospital Huddinge. Biopsies were minced and placed in $35 \mathrm{~mm}$ dishes (Corning Incorporated, Corning NY, USA) under a sterile glass coverslip and cultured in DMEM Glutamax, 10 mM HEPES, 1X MEM amino acids, 1X sodium pyruvate supplemented with $100 \mathrm{U} / \mathrm{ml}$ penicillin, $100 \mu \mathrm{g} / \mathrm{ml}$ streptomycin, $15 \%$ fetal calf serum (all from Invitrogen, Paisley, UK), in a humidified $37^{\circ} \mathrm{C}, 5 \% \mathrm{CO}_{2}$ incubator. The regional ethics committee approved the study (04273/1, supplements 2006/637-32 and 2009-06-12).

\section{Cytokine treatment}

After 2 passages, cells were seeded into 6-well plates (Corning Inc.). At confluence, cytokine treatment was performed during 48 hours using human recombinant TNF- $\alpha 100 \mathrm{U} / \mathrm{ml}$ or IFN- $\gamma 200 \mathrm{U} / \mathrm{ml}$ (PeproTech, London, U.K.) in serum-free media, otherwise as above. Experiments were ended by removal and freezing of the supernatants and addition of lysis buffer to the cell monolayer, see below.

\section{RNA extraction and reverse transcription}

Total RNA was extracted from the cells using the RNeasy Mini kit (Qiagen, GmbH, Hilden, Germany). The amount and purity of the RNA was assessed by spectrophotometry using a Nanodrop ND-1000
(NanoDrop Technologies, Wilmington, DE, USA). Total RNA (250 ng) was subsequently treated with 1 unit of amplification grade DNase I (Invitrogen) for $15 \mathrm{~min}$ at room temperature and inactivated by the addition of 2.5 $\mathrm{mM}$ EDTA followed by incubation at $65^{\circ} \mathrm{C}$ for $10 \mathrm{~min}$ according to the manufacturer's instructions. The DNase-treated RNA was subsequently reverse transcribed in $20 \mu \mathrm{l}$ reactions containing the following reagents from Invitrogen; $250 \mathrm{ng}$ of Oligo(dT) primer, 1 $\times$ First Strand Buffer, $10 \mathrm{mM}$ DTT and $500 \mu \mathrm{M}$ of each dNTP and $100 \mathrm{U}$ Superscript II. cDNA synthesis was allowed to proceed for $1 \mathrm{~h}$ at $42^{\circ} \mathrm{C}$ before inactivation at $72^{\circ} \mathrm{C}$ for $10 \mathrm{~min}$.

\section{Real-time PCR and data analysis}

One $\mu \mathrm{l}$ cDNA templates were added to triplicate $25 \mu \mathrm{l}$ reaction mixtures using Platinum SYBR Green qPCR Supermix UDG (Invitrogen). An ABI Prism 7500 realtime thermocycler was used (Applied Biosystems, Palo Alto, CA, USA). Primers (Invitrogen) are provided in Table 1 . Threshold cycle $(\mathrm{Ct})$ values from the exponential phase of the PCR amplification plot for each target transcript were normalized to that encoding glyceraldehyd-3-phosphate dehydrogenase (GAPDH). From these values, fold-differences in the levels of transcripts

Table 1 Transcripts analyzed by real-time PCR, gene symbols and primer sequences

\begin{tabular}{|c|c|c|c|}
\hline $\begin{array}{c}\text { Target } \\
\text { transcript }\end{array}$ & Gene & Polarity & Sequence $\left(5^{\prime} \rightarrow 3^{\prime}\right)$ \\
\hline \multirow[t]{2}{*}{ IDO1 } & INDO & Sense & GCATTITCAGTGTTCTTCGCATA \\
\hline & & Anti-sense & CATACACCAGACCGTCTGATAGCT \\
\hline \multirow[t]{2}{*}{ TDO } & TDO2 & Sense & GAACATCTIITATCATAACTCATCAAGCT \\
\hline & & Anti-sense & ACAACCTTAAGCATGTTCCTITCAT \\
\hline \multirow[t]{2}{*}{$\mathrm{KMO}$} & $K M O$ & Sense & TGTAATCCTCCAAGCTTCAATCTG \\
\hline & & Anti-sense & CTAGTAGATGCCCACTGAATATTTGTG \\
\hline \multirow[t]{2}{*}{ HAAO } & HAAO & Sense & GGACGTTCTGTITGAGAAGTGGTT \\
\hline & & Anti-sense & AGCTGAAGAACTCCTGGATGATG \\
\hline \multirow[t]{2}{*}{ KAT1 } & $C C B L 1$ & Sense & CCTGCTAAGGCTCAGGTATAACCT \\
\hline & & Anti-sense & GGACTCAAGCCTAAAGGCAACTC \\
\hline \multirow[t]{2}{*}{ KAT2 } & AADAT & Sense & CACATCTGGCAGCCAACAAG \\
\hline & & Anti-sense & CACTGGCAACATTAATAATGTTGCA \\
\hline \multirow[t]{2}{*}{ KAT3 } & $C C B L 2$ & Sense & ACTATCAGCCATCCCCGTTC \\
\hline & & Anti-sense & AATGAAGCAAAAACGCACAAACT \\
\hline \multirow[t]{2}{*}{ KAT4 } & GOT2 & Sense & TGTGGTGTGCAGCCTCTCAT \\
\hline & & Anti-sense & AAGCCTGAACCCAGCTAGCA \\
\hline \multirow[t]{2}{*}{ KYNU } & KYNU & Sense & ACAGGATCTGCCTCCAGTTGA \\
\hline & & Anti-sense & TGGCCCACTTATCTAGTTCTTCTTC \\
\hline \multirow[t]{2}{*}{ QPRT } & QPRT & Sense & ACACCGGCCATGGGTTAAC \\
\hline & & Anti-sense & GCCCCATTGGCCACTGA \\
\hline \multirow[t]{2}{*}{ GAPDH } & GAPDH & Sense & CACATGGCCTCCAAGGAGTAA \\
\hline & & Anti-sense & TGAGGGTCTCTCTCTTCCTCTTGT \\
\hline
\end{tabular}


between individual untreated and treated cell cultures were calculated according to the formula $2^{-\Delta \Delta \mathrm{Ct}}$ [27].

\section{Analysis of kynurenic acid levels}

Cell culture supernatants $(1.0 \mathrm{ml})$ were collected and kept in $-20^{\circ} \mathrm{C}$ until analysis. In order to precipitate residual protein, samples were centrifuged at $20800 \mathrm{~g}$ for 5 minutes and an equal volume of $0.4 \mathrm{M}$ perchloric acid was added to the supernatants. After a second centrifugation $70 \%$ perchloric acid $(300 \mu \mathrm{l})$ was added, and thereafter the supernatants were centrifuged twice at $20800 \mathrm{~g}$ for 5 minutes.

Analysis of KYNA was performed using an isocratic reversed-phase high-performance liquid chromatography (HPLC) system, including a dual-piston, high-liquid delivery pump (Bischoff Chromatography, Leonberg, Germany), a ReproSil-Pur C18 column $(150 \times 4 \mathrm{~mm}$, Dr. Maisch GmbH, Ammerbuch, Germany) and a fluorescence detector (FP 2020, Jasco Ltd., Hachioji City, Japan) with an excitation wavelength of $344 \mathrm{~nm}$ and an emission wavelength of $398 \mathrm{~nm}$ (18 nm bandwidth). A mobile phase of $50 \mathrm{mM}$ sodium acetate $(\mathrm{pH} 6.2$, adjusted with acetic acid) and $7.0 \%$ acetonitrile was pumped through the reversed-phase column at a flow rate of $0.5 \mathrm{~mL} / \mathrm{min}$. Samples of $50 \mu \mathrm{L}$ were manually injected into a Rheodyne injector with a sample loop of $50 \mu \mathrm{l}$ (Rheodyne, Rhonert Park, CA, USA). Zinc acetate (0.5 $\mathrm{M}$ not $\mathrm{pH}$ adjusted) was delivered postcolumn by a peristaltic pump (P-500; Pharmacia, Uppsala, Sweden) at a flow rate of $0.10 \mathrm{ml} / \mathrm{hr}$. Signals from the fluorescence detector were transferred to a computer for analysis with Datalys Azur software (Datalys, Grenoble, France). The retention time of KYNA was about 7-8 minutes. Initially, the sensitivity of the system was verified by analysis of a standard mixture of KYNA with concentrations from 1 to $30 \mathrm{nM}$, which resulted in a linear standard plot.

\section{Statistics}

Comparisons across treatments were done by repeated measures ANOVA with Bonferroni's Multiple Comparison Test using GraphPad (GraphPad Software, Inc., San Diego, CA, USA).

\section{Results}

Detection of transcripts encoding KP enzymes

All the investigated kynurenine pathway transcripts (IDO1, TDO, KAT1, KAT2, KAT3, KAT4, KMO, KYNU, HAAO, QPRT) were detected in untreated fibroblast cell cultures, Figure 1. The levels of expression varied considerably across the different genes, with transcripts encoding IDO1 detected at the lowest level and those encoding KAT3 detected at the highest level (difference $8 \times 10^{3}$ fold). The variation across individual

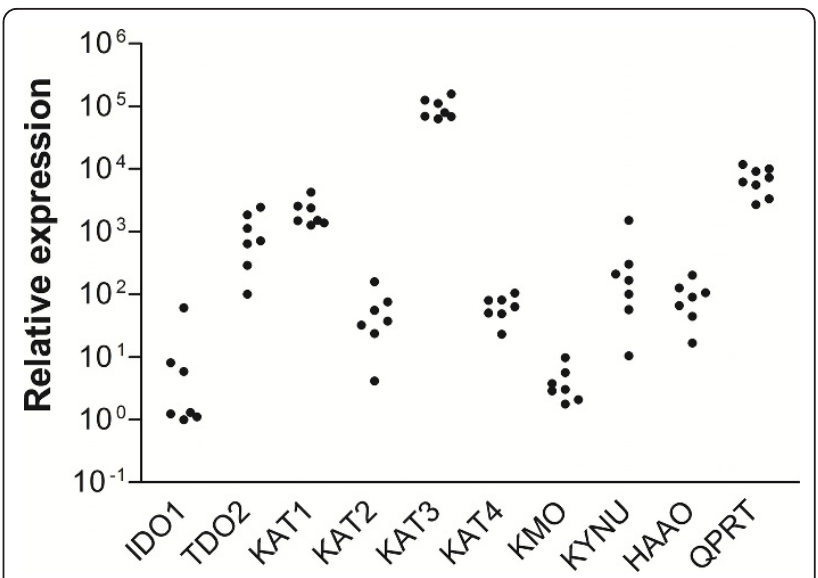

Figure 1 Relative levels of transcripts encoding enzymes in the kynurenine pathway in human skin-derived fibroblasts from 7 individuals. Transcripts encoding the following enzymes were investigated; Indoleamine 2,3-dioxygenase 1 (IDO1), Tryptophan 2,3dioxygenase (TDO), Kynurenine aminotransferases (KAT) 1-4, Kynurenine 3-monooxygenase (KMO), Kynureninase (KYNU), 3Hydroxyanthranilic acid oxygenase (HAAO) and Quinolinic acid phosphoribosyltransferase (QPRT).

cultures $(\mathrm{n}=7)$, ranged from 2.5 (KAT3) to 145 -fold (KYNU).

\section{Modulation of transcript-levels by IFN- $\gamma$ and/or TNF- $\alpha$}

The potential effects of IFN- $\gamma$, TNF- $\alpha$, or a combination of IFN- $\gamma$ and TNF- $\alpha$ on kynurenine pathway transcripts were investigated in the fibroblast cell cultures, see Figure 2. The levels of transcripts encoding IDO1 were significantly increased ( $>10^{5}$-fold) in cultures treated with IFN- $\gamma(\mathrm{p}<0.001)$ as well as IFN- $\gamma$ together with TNF- $\alpha$ $(\mathrm{p}<0.001)$ compared to untreated cultures although no effect of TNF- $\alpha$ alone was observed (Figure 2A). Transcripts encoding tryptophan 2,3-dioxygenase (TDO), on the other hand, were significantly down-regulated in cultures treated with a combination of IFN- $\gamma$ and TNF$\alpha$ (20-fold; $p<0.001)$ as compared to untreated cells or cells treated with the individuals cytokines (Figure 2B). Moreover, levels of transcripts encoding the kynurenine aminotransferases (KATs) were either unaffected or down-regulated by the cytokine treatments. Whereas KAT2 was unaffected by cytokine treatment, KAT1 and KAT3 transcript levels were reduced following treatment with the combination of IFN- $\gamma$ and TNF- $\alpha$ (2.6fold, $\mathrm{p}<0.001$ and 1.7 -fold, $\mathrm{p}<0.01$ respectively, Figure $2 \mathrm{C}, \mathrm{D}$ and $2 \mathrm{E}$ ). Levels of transcripts encoding mitochondrial aspartate aminotransferase (mitAAT, i.e KAT4) were significantly down regulated (1.5-fold) in cultures treated with IFN- $\gamma(\mathrm{p}<0.05)$ and further decreased with the combination of IFN- $\gamma$ and TNF- $\alpha$ (2.7-fold; $\mathrm{p}<$ 0.001 , Figure $2 \mathrm{~F}$ ). Levels of transcripts encoding kynurenine 3-monooxygenase (KMO) observed in the 


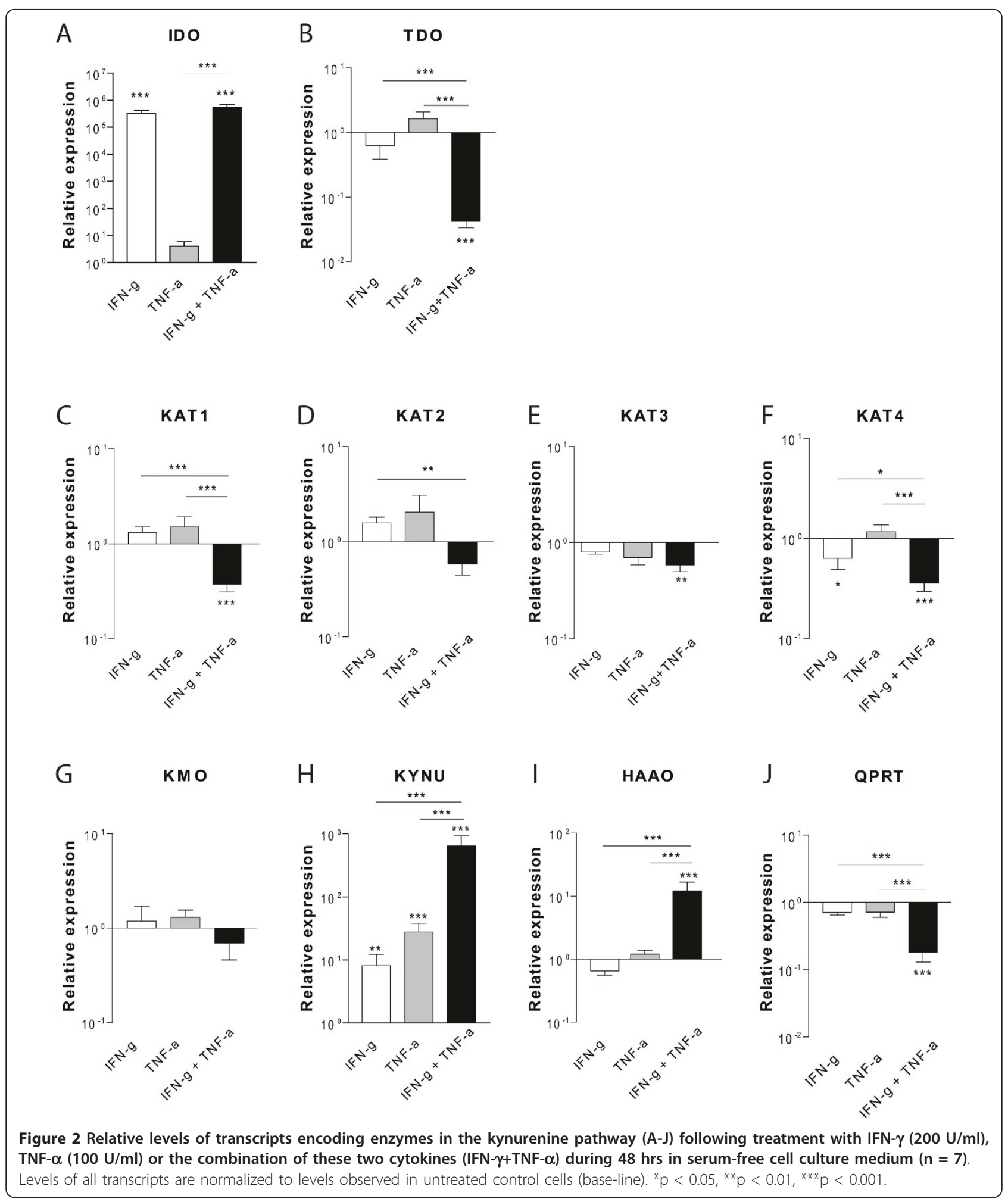

fibroblast cultures were not significantly affected by the cytokine treatment (Figure 2G). Levels of transcripts encoding kynureninase (KYNU) were up-regulated following IFN- $\gamma$ treatment $(8$-fold; $\mathrm{p}<0.01)$ or with TNF- $\alpha$ treatment (28-fold; $\mathrm{p}<0.001$ ). A further increase in the levels of KYNU transcripts was observed with the combination of IFN- $\gamma$ and TNF- $\alpha$ (650-fold; $\mathrm{p}<0.001$, Figure 2H). Levels of transcripts encoding 3- 
hydroxyanthranilate 3,4-dioxygenase (HAAO) were up regulated only in cultures treated with the combination of IFN- $\gamma$ and TNF- $\alpha$ (12-fold, $\mathrm{p}<0.001$, Figure 2I). Levels of transcripts encoding quinolinate phosphoribosyltransferase (QPRT) were down-regulated by the combination of IFN- $\gamma$ and TNF- $\alpha$ (5-fold, $\mathrm{p}<0.001$ ), but unaffected by the individual cytokines (Figure 2J).

\section{Effects on KYNA levels}

To address potential functionality of the KP in these human fibroblast cultures, we measured the accumulation of KYNA, one of the end metabolites in the KP in the supernatants. Levels of KYNA were detectable in supernatants from untreated ex vivo fibroblast cultures $(3.4 \pm 0.6 \mathrm{nmol} / \mathrm{l})$. Significantly $(\mathrm{p}<0.0001)$ higher levels were detected in supernatants of cells treated with IFN- $\gamma(27.2 \pm 18 \mathrm{nmol} / \mathrm{l})$ or with IFN- $\gamma$ and TNF- $\alpha$ $(39.8 \pm 20.1 \mathrm{nmol} / \mathrm{l})$ as compared to supernatants from untreated cells. TNF- $\alpha$ alone did not cause a significant increase in the accumulation of KYNA.

\section{Discussion}

We here report, for the first time, that human skin fibroblast cultures express detectable levels of transcripts encoding the different enzymes of the KP. Substantial differences in the basal levels of expression across genes and individuals were observed which are likely to be explained by genetic and epigenetic variation between individual cultures. Following treatment with IFN- $\gamma$, these cultures exhibited relative increases of $>10^{5}$-fold for transcripts encoding IDO1. We also found that human skin fibroblast cultures can release KYNA, and that this release was significantly increased following IFN- $\gamma$, but not TNF- $\alpha$, treatment, indicating that at least some of the transcriptional changes observed in response to IFN- $\gamma$ are functional in these cells.

Thus, in agreement with previous reports [28,29], human fibroblast cultures appear to be able to increase the rate of tryptophan degradation along the kynurenine pathway in response to IFN- $\gamma$ treatment. Our present findings support the notion that IDO1 is the major determinant of this response in human fibroblasts, as is also the case in many other cell types, derived both from the brain and from peripheral tissues [30]. For example, Guillemin and co-workers reported increased levels of KYNA and increased levels of transcripts encoding IDO1 following IFN- $\gamma$, but not following TNF$\alpha$ treatment of human fetal astrocytes [23]. More recently, increased levels of KYNA and transcripts encoding IDO1 were also observed in primary neurons and neuroblastoma cells following IFN- $\gamma$ treatment [22].

While Heyes and colleagues [31] reported a small increase in KMO activity in monocytes following IFN- $\gamma$ treatment, we did not observe any significant effect on transcripts encoding KMO following cytokine treatment. Our observations are thus in agreement with the effects of IFN- $\gamma$ observed in neuronal cells [22]. Whereas IFN- $\gamma$ or TNF- $\alpha$, alone or in combination, markedly increased transcripts of KYNU and HAAO, we observed no effect or even decreased levels of transcripts encoding KAT enzymes by these cytokines. Indeed there is no consensus in earlier studies regarding the response of the KAT enzymes to IFN- $\gamma$ treatment. Whereas increases in the levels of KAT 1 and KAT 2 were observed in fetal astrocytes following IFN- $\gamma$ treatment [23], no effect on the levels of transcripts encoding these enzymes was observed in neuronal cells [22]. In neuroblastoma cells, levels of transcripts encoding TDO were reduced by the IFN- $\gamma$ treatment whereas no effects on the levels of transcripts encoding KAT1, KAT2, KYNU, KMO, HAAO or QPRT were observed [22]. Differences in transcription of genes encoding enzymes involved in the KP in response to IFN- $\gamma$ therefore most likely exist across cell types. These differences probably also explain some of the differences observed across cell types in their enzyme activities and in their abilities to form kynurenine and quinolinic acid [31]. The physiological role of the kynurenine pathway in skin-derived fibroblasts is not known but may involve effects not primarily related to acetylcholine or glutamate receptors such as effects on cell proliferation [1], cytokine release [32] or microbial growth $[21,24-26,33]$ as described in other peripheral cell types.

The increases in KYNU and HAAO, and decrease in levels of transcripts encoding QPRT, following IFN- $\gamma$ and TNF- $\alpha$ treatment suggest that such treatment can potentially alter the accumulation of other metabolites generated by the KP, such as quinolinic acid. It should also be noted that TNF- $\alpha$ treatment alone caused a pronounced and selective increase (almost 30-fold) in levels of transcripts encoding KYNU, suggesting a direct influence of TNF- $\alpha$ on expression of this gene. Thus, it appears as if certain cytokines can differentially affect expression of genes in the KP, at least in fibroblasts (for overview see Figure 3), and thereby potentially modulate levels of individual metabolites.

Fibroblast cultures derived from patients and healthy controls have previously been used to study a range of CNS-diseases. For example, in fibroblasts from patients with schizophrenia, alterations in pathways involved in cell cycle regulation and RNA processing have been identified [34]. Moreover, alterations in growth, morphology, cell adhesion, apoptotic pathways, composition of phospholipid fatty acids in the plasma membrane and glutathione synthesis are reported [35-39]. Aberrant amino acid transport has been identified in fibroblast from patients with schizophrenia, bipolar disorder as well as autism [40-42]. These reports suggest that 


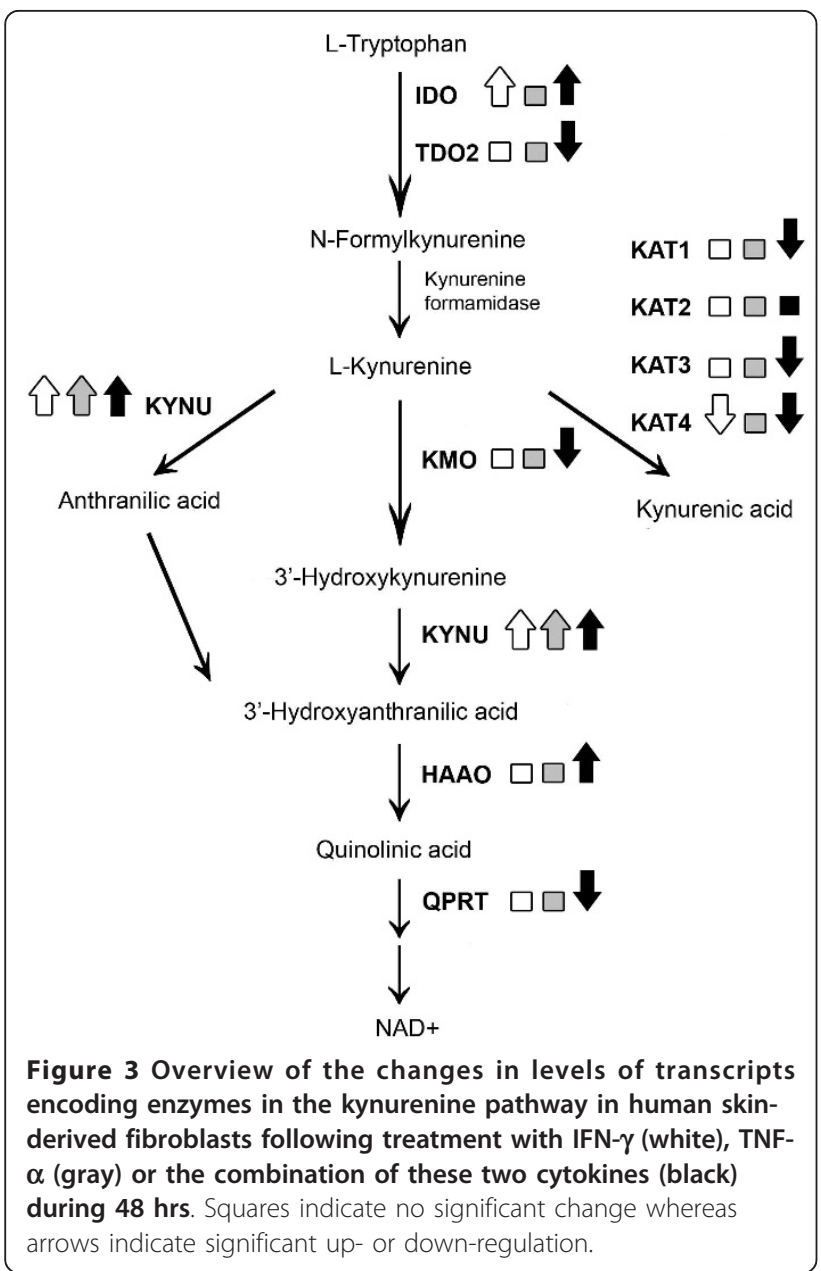

peripheral tissues can be used to identify alterations at the molecular level in patients with psychiatric disorders and thus provide a useful method to investigate mechanisms underlying such disorders. The advantage of studying ex vivo cultures compared to postmortem tissue or blood samples is that in such cultures confounding factors like medical treatments are minimized. Furthermore, in contrast to using clinical samples, $e x$ vivo cell cultures can also be used to conduct well-controlled studies of potential gene-environment interactions. The present findings suggest that fibroblast cultures can be used to study disease-related abnormalities in the kynurenine pathway of tryptophan degradation.

\section{Acknowledgements}

The present study was supported by the Stanley Medical Research Institute, the Swedish Research Council (HK, GSL), Fredrik och Ingrid Thurings Stiftelse (LA, ASJ), Söderström-Königska and Wolffs stiftelser (GSL), and Swedish Medical Society (GSL).

\section{Author details}

'Department of Neuroscience, Karolinska Institutet, Retzius väg 8, 17177 Stockholm, Sweden. ${ }^{2}$ Department of Clinical Neuroscience, Karolinska Institutet, Section of Psychiatry at Karolinska University Hospital Huddinge, 14186 Stockholm, Sweden. ${ }^{3}$ Department of Experimental and Clinical Pharmacology, Medical University, Lublin, Jaczewskiego 8, 20-090 Lublin, Poland. ${ }^{4}$ Department of Toxicology, Institute of Agricultural Medicine, Lublin, Jaczewskiego 2, 20-950 Lublin, Poland. ${ }^{5}$ Department of Physiology and Pharmacology, Karolinska Institutet, Nanna Svartz väg 2, 17177 Stockholm, Sweden.

\section{Authors' contributions}

BOL performed biopsies. ASJ performed cell cultures. LA and AM carried out the RNA analyses. MK carried out the KYNA analyses. LA performed all statistical analyses. EMU, TK participated in the design of the study. HK, GE, GSL and EMU conceived of the study, and participated in its design and coordination. HK drafted the manuscript. All authors helped to revise the first draft of the manuscript and all authors approved the final manuscript.

\section{Competing interests}

The authors declare that they have no competing interests.

Received: 6 May 2011 Accepted: 8 October 2011

Published: 8 October 2011

\section{References}

1. Moffett JR, Namboodiri MA: Tryptophan and the immune response. Immunol Cell Biol 2003, 81(4):247-265.

2. Stone TW: Neuropharmacology of quinolinic and kynurenic acids. Pharmacol Rev 1993, 45(3):309-379.

3. Hilmas C, Pereira EF, Alkondon M, Rassoulpour A, Schwarcz R, Albuquerque EX: The brain metabolite kynurenic acid inhibits alpha7 nicotinic receptor activity and increases non-alpha7 nicotinic receptor expression: physiopathological implications. J Neurosci 2001, 21(19):7463-7473.

4. Zmarowski A, Wu HQ, Brooks JM, Potter MC, Pellicciari R, Schwarcz R, Bruno JP: Astrocyte-derived kynurenic acid modulates basal and evoked cortical acetylcholine release. Eur J Neurosci 2009, 29(3):529-538.

5. Nilsson LK, Linderholm KR, Engberg G, Paulson L, Blennow K, Lindstrom LH, Nordin C, Karanti A, Persson P, Erhardt S: Elevated levels of kynurenic acid in the cerebrospinal fluid of male patients with schizophrenia. Schizophr Res 2005, 80(2-3):315-322.

6. Schwarcz R, Rassoulpour A, Wu HQ, Medoff D, Tamminga CA, Roberts RC: Increased cortical kynurenate content in schizophrenia. Biol Psychiatry 2001, 50(7):521-530.

7. Guidetti P, Luthi-Carter RE, Augood SJ, Schwarcz R: Neostriatal and cortical quinolinate levels are increased in early grade Huntington's disease. Neurobiol Dis 2004, 17(3):455-461.

8. Erhardt S, Blennow K, Nordin C, Skogh E, Lindstrom LH, Engberg G: Kynurenic acid levels are elevated in the cerebrospinal fluid of patients with schizophrenia. Neurosci Lett 2001, 313(1-2):96-98.

9. Gabbay V, Klein RG, Katz Y, Mendoza S, Guttman LE, Alonso CM, Babb JS, Hirsch GS, Liebes $L$ : The possible role of the kynurenine pathway in adolescent depression with melancholic features. J Child Psychol Psychiatry 51(8):935-943.

10. Myint AM, Kim YK, Verkerk R, Scharpe S, Steinbusch H, Leonard B: Kynurenine pathway in major depression: evidence of impaired neuroprotection. J Affect Disord 2007, 98(1-2):143-151.

11. Myint AM, Kim YK, Verkerk R, Park SH, Scharpe S, Steinbusch HW, Leonard BE: Tryptophan breakdown pathway in bipolar mania. J Affect Disord 2007, 102(1-3):65-72.

12. Miller $C L$, Llenos $I C$, Dulay JR, Weis $S$ : Upregulation of the initiating step of the kynurenine pathway in postmortem anterior cingulate cortex from individuals with schizophrenia and bipolar disorder. Brain Res 2006, 10731074:25-37.

13. Olsson SK, Samuelsson M, Saetre P, Lindstrom L, Jonsson EG, Nordin C, Engberg G, Erhardt S, Landen M: Elevated levels of kynurenic acid in the cerebrospinal fluid of patients with bipolar disorder. J Psychiatry Neurosci 2010, 35(3):195-199. 
14. Asp L, Holtze M, Powell SB, Karlsson H, Erhardt S: Neonatal infection with neurotropic influenza $A$ virus induces the kynurenine pathway in early life and disrupts sensorimotor gating in adult Tap1-/- mice. Int $J$ Neuropsychopharmacol 2009, 1-11.

15. Erhardt S, Schwieler L, Emanuelsson C, Geyer M: Endogenous kynurenic acid disrupts prepulse inhibition. Biol Psychiatry 2004, 56(4):255-260.

16. Potter MC, Elmer Gl, Bergeron R, Albuquerque EX, Guidetti P, Wu HQ, Schwarcz R: Reduction of endogenous kynurenic acid formation enhances extracellular glutamate, hippocampal plasticity, and cognitive behavior. Neuropsychopharmacology 35(8):1734-1742.

17. Laugeray A, Launay JM, Callebert J, Surget A, Belzung C, Barone PR: Peripheral and cerebral metabolic abnormalities of the tryptophankynurenine pathway in a murine model of major depression. Behav Brain Res 210(1):84-91.

18. Chess AC, Simoni MK, Alling TE, Bucci DJ: Elevations of endogenous kynurenic acid produce spatial working memory deficits. Schizophr Bull 2007, 33(3):797-804.

19. Ting KK, Brew BJ, Guillemin GJ: Effect of quinolinic acid on human astrocytes morphology and functions: implications in Alzheimer's disease. J Neuroinflammation 2009, 6:36.

20. Rahman A, Ting K, Cullen KM, Braidy N, Brew BJ, Guillemin GJ: The excitotoxin quinolinic acid induces tau phosphorylation in human neurons. PLoS One 2009, 4(7):e6344.

21. Pfefferkorn ER: Interferon gamma blocks the growth of Toxoplasma gondii in human fibroblasts by inducing the host cells to degrade tryptophan. Proc Natl Acad Sci USA 1984, 81(3):908-912.

22. Guillemin GJ, Cullen KM, Lim CK, Smythe GA, Garner B, Kapoor V, Takikawa O, Brew BJ: Characterization of the kynurenine pathway in human neurons. J Neurosci 2007, 27(47):12884-12892.

23. Guillemin GJ, Kerr SJ, Smythe GA, Smith DG, Kapoor V, Armati PJ, Croitoru J, Brew BJ: Kynurenine pathway metabolism in human astrocytes: a paradox for neuronal protection. J Neurochem 2001, 78(4):842-853.

24. Gupta SL, Carlin JM, Pyati P, Dai W, Pfefferkorn ER, Murphy MJ Jr: Antiparasitic and antiproliferative effects of indoleamine 2,3dioxygenase enzyme expression in human fibroblasts. Infect Immun 1994, 62(6):2277-2284

25. Dai W, Pan H, Kwok O, Dubey JP: Human indoleamine 2,3-dioxygenase inhibits Toxoplasma gondii growth in fibroblast cells. J Interferon Res 1994, 14(6):313-317.

26. Spekker K, Czesla M, Ince V, Heseler K, Schmidt SK, Schares G, Daubener W: Indoleamine 2,3-dioxygenase is involved in defense against Neospora caninum in human and bovine cells. Infect Immun 2009, 77(10):4496-4501.

27. Livak KJ, Schmittgen TD: Analysis of relative gene expression data using real-time quantitative PCR and the 2(-Delta Delta $C(T))$ Method. Methods 2001, 25(4):402-408

28. Byrne Gl, Lehmann LK, Kirschbaum JG, Borden EC, Lee CM, Brown RR: Induction of tryptophan degradation in vitro and in vivo: a gammainterferon-stimulated activity. J Interferon Res 1986, 6(4):389-396.

29. Daubener W, MacKenzie CR: IFN-gamma activated indoleamine 2,3dioxygenase activity in human cells is an antiparasitic and an antibacterial effector mechanism. Adv Exp Med Biol 1999, 467:517-524.

30. King NJ, Thomas SR: Molecules in focus: indoleamine 2,3-dioxygenase. Int J Biochem Cell Biol 2007, 39(12):2167-2172.

31. Heyes MP, Chen CY, Major EO, Saito K: Different kynurenine pathway enzymes limit quinolinic acid formation by various human cell types. Biochem J 1997, 326(Pt 2):351-356.

32. Di Serio C, Cozzi A, Angeli I, Doria L, Micucci I, Pellerito S, Mirone P, Masotti G, Moroni F, Tarantini F: Kynurenic acid inhibits the release of the neurotrophic fibroblast growth factor (FGF)-1 and enhances proliferation of glia cells, in vitro. Cell Mol Neurobiol 2005, 25(6):981-993.

33. Kuc D, Rahnama M, Tomaszewski T, Rzeski W, Wejksza K, UrbanikSypniewska T, Parada-Turska J, Wielosz M, Turski WA: Kynurenic acid in human saliva-does it influence oral microflora? Pharmacol Rep 2006, 58(3):393-398.

34. Wang L, Lockstone HE, Guest PC, Levin Y, Palotas A, Pietsch S, Schwarz E, Rahmoune H, Harris LW, Ma D, Bahn S: Expression profiling of fibroblasts identifies cell cycle abnormalities in schizophrenia. J Proteome Res 2010, 9(1):521-527.

35. Mahadik SP, Mukherjee S, Laev H, Reddy R, Schnur DB: Abnormal growth of skin fibroblasts from schizophrenic patients. Psychiatry Res 1991, 37(3):309-320.
36. Mahadik SP, Mukherjee S, Wakade CG, Laev H, Reddy RR, Schnur DB: Decreased adhesiveness and altered cellular distribution of fibronectin in fibroblasts from schizophrenic patients. Psychiatry Res 1994, 53(1):87-97.

37. Catts VS, Catts SV, McGrath JJ, Feron F, McLean D, Coulson EJ, LutzeMann LH: Apoptosis and schizophrenia: a pilot study based on dermal fibroblast cell lines. Schizophr Res 2006, 84(1):20-28.

38. Gysin R, Kraftsik R, Sandell J, Bovet P, Chappuis C, Conus P, Deppen P, Preisig M, Ruiz V, Steullet P, Tosic M, Werge T, Cuenod M, Do KQ: Impaired glutathione synthesis in schizophrenia: convergent genetic and functional evidence. Proc Natl Acad Sci USA 2007, 104(42):16621-16626.

39. Mahadik SP, Mukherjee S, Horrobin DF, Jenkins K, Correnti EE, Scheffer RE: Plasma membrane phospholipid fatty acid composition of cultured skin fibroblasts from schizophrenic patients: comparison with bipolar patients and normal subjects. Psychiatry Res 1996, 63(2-3):133-142.

40. Persson ML, Johansson J, Vumma R, Raita J, Bjerkenstedt L, Wiesel FA, Venizelos N: Aberrant amino acid transport in fibroblasts from patients with bipolar disorder. Neurosci Lett 2009, 457(1):49-52.

41. Flyckt L, Venizelos N, Edman G, Bjerkenstedt L, Hagenfeldt L, Wiesel FA: Aberrant tyrosine transport across the cell membrane in patients with schizophrenia. Arch Gen Psychiatry 2001, 58(10):953-958.

42. Fernell E, Karagiannakis A, Edman G, Bjerkenstedt L, Wiesel FA, Venizelos N: Aberrant amino acid transport in fibroblasts from children with autism. Neurosci Lett 2007, 418(1):82-86.

\section{doi:10.1186/1476-9255-8-25}

Cite this article as: Asp et al.: Effects of pro-inflammatory cytokines on expression of kynurenine pathway enzymes in human dermal fibroblasts. Journal of Inflammation 2011 8:25.

\section{Submit your next manuscript to BioMed Central and take full advantage of:}

- Convenient online submission

- Thorough peer review

- No space constraints or color figure charges

- Immediate publication on acceptance

- Inclusion in PubMed, CAS, Scopus and Google Scholar

- Research which is freely available for redistribution

Submit your manuscript at www.biomedcentral.com/submit
C Biomed Central 